\title{
The Long Bubbles Penetration through Viscoelastic Fluids with Shear-Thinning Viscosity in a Curved Tube
}

\author{
Ching-Chuan Chang \\ Department of Mechanical Engineering, Army Academy R.O.C., Taoyuan, Taiwan \\ Correspondence should be addressed to Ching-Chuan Chang; nashsccc8142@yahoo.com.tw
}

Received 8 August 2016; Revised 22 January 2017; Accepted 24 January 2017; Published 19 February 2017

Academic Editor: Luigi Nicolais

Copyright ( 2017 Ching-Chuan Chang. This is an open access article distributed under the Creative Commons Attribution License, which permits unrestricted use, distribution, and reproduction in any medium, provided the original work is properly cited.

\begin{abstract}
The purpose of this research is to investigate the behavior of a long bubbles penetrating through viscoelastic fluids in a curved tube. The injection gas flow is controlled by a mass flow controller (MFC). The results of the experiments show that the bubbles width approaches constant value at the location six-diameter upstream from the bubbles front. A difference variable is introduced at the six-diameter location to show the shifting deviation of the bubbles in the curved tube. It is shown that, with the same fluid viscosity and the curved angle, the difference is higher when the gas flow rate is higher. Also, the difference increases proportionally when the capillary number and the Weissenberg number increase.
\end{abstract}

\section{Introduction}

The principle of gas-assisted injection molding (GAIM) is to use high-pressure inert gas injection into the molten plastic forming vacuum melt section and push forward to achieve injection molding, packing, cooling, and other processes. Since the gas has an efficient transfer of pressure, it allows the internal pressure consistent throughout. Thus it can eliminate internal stress and prevent product deformation, while significantly reducing the pressure of the mold cavity. In addition, GAIM also can reduce the product weight, eliminate sink marks, improve production efficiency, improve product design freedom, and so on. GAIM has been extensively adopted to manufacture the components of the automobiles, home appliances, communication products, computer chasses, and other items.

Early scholars Saffman and Taylor [1] use tablet mode to shoot the shape of the bubble when water flows through oil and oil flow through glycerin. Taylor [2] discusses Newtonian fluid when the hollow ratio is changed in the straight tube, taken at a distance of 1.5 times the diameter of the tube from bubble tip; the bubble diameter will tend to constant value. Taylor [2] proposed three possible streamline patterns in the bubble front manifold. At high capillary number (Ca) value, the fluid will occur completely through flow field, which does not show the recirculation zone on free surface.
At lower $\mathrm{Ca}$ another possible two flow fields will appear, which are transitional stream and recirculation. Kolb and Cerro [3] published research in long bubble-driven flow pattern in square pipe, which found that fractional converge (m) will be close to 0.64 at high $\mathrm{Ca}$ values. Wong et al. $[4,5]$ experimentally and theoretically analyze that the long bubble in the square pipe drives viscosity fluid. Huzyak and Koelling [6] experimentally investigate the differences between Newtonian fluid and non-Newtonian fluid driven by long bubble condition and pointed out in the text that the relationship between $\mathrm{Ca}$ and $\mathrm{m}$ is irrelevant with pipe diameter in terms of Newtonian fluid, but that will be affected by pipe diameter in terms of viscoelastic fluid. Paper explores the relationship between Deborah number (De) and $m$. Gauri and Koelling [7] continued its experimental architecture and used particle tracking velocimetry to measure flow field of bubble front; the flow field results agree with two flow fields of full transitional stream and recirculation proposed in Taylor [2]. Bi and Zhao [8] use four different cross-sectional shapes of the tube, which is circle, triangular, square, and rectangular tubes; the tube was filled with water and placed vertically and gas was injected in the bottom of the pipe, shooting bubble continuous growth figure of different shapes of tubes by camera. The experimental results showed that it have faster growth of the bubble when the pipe diameter is larger. Yang and Chou [9] investigate the distribution of residual 
wall thickness of GAIM tube member at diameter junction and bend. Gas passing through the bend cavity will tend to the inside, resulting in nonuniform wall thickness inside and outside and empting the area eccentric phenomena after the gas is blown. Yamamoto et al. [10] analyzed Newtonian and non-Newtonian fluids using experimental methods and investigate the effect of $\mathrm{Ca}$ and $\mathrm{Wi}$ to $m$. Sousa et al. [11] use the experimental model; the non-Newtonian fluid polyacrylamide (PAA) is injected into the vertical tube by the CCD camera captured images of bubbles, and then the shape of the bubble with a dimensionless manner is presented. Hsu et al. [12] simulated two flow fields mentioned by Taylor [2] using numerical analysis method. Their result also found that there is a conversion flow field between the two flow fields. Ha-Ngoc and Fabre [13] use numerical methods to simulate the bubble shape under different conditions with dimensionless bubble length and width. Hsu et al. [14] investigate the long bubble penetrating the silicone oil in the tube; when the viscosity of the silicone oil is fixed, the gas flow rate is higher and the $\mathrm{Ca}$ and Reynolds number (Re) are larger. Cheng-Hsing Hsu et al. [15] investigate the long bubble penetrating volatile organic compounds; when the Re values for acetone, methyl alcohol, and butyl acetate were between 4381 4430, 2460 2490, and 1940 1980, respectively, the transient response phenomenon occurred. Chang et al. [16] experimental results showed that bubble velocity, capillary number, and Weissenberg number increase as shear viscosity increases under a constant gas flow by mass flow controller. However, as shear viscosity increases, bubble diameter decreases and $\mathrm{m}$ increases.

From the past related studies, we found that most experiments on long bubbles are focused on the bubble contour and the use of runner of round straight tube to observe the bubbles change of the Newtonian fluid, compared with no change in the development of flow path of other shapes. Therefore, the present research uses a non-Newtonian fluid, with the use of three kinds of curved tube of 90 degrees, 135 degrees, and 180 degrees, as observing the flow variation of double-flow runner.

\section{Experiment}

2.1. Experimental Setup. The architecture of experiment consults that of Hsu et al. [14]. Figure 1 shows the experimental setup for the gas penetration. The images of the bubbles are captured by a high-speed camera (CASIO EX-F1) with 6 Mega pixel/60 frames per second in order to observe the change of the flow field involved bubbles and flow type. The camera output pixel is 600 million pixels and the highest animation resolution is $1920 \times 1080$ pixels. The light source is a halogen spotlight source (LA180-Me) which is characterized by $180 \mathrm{~W}$ metal halide lamp and the average brightness of 2.5 million lux. Nitrogen with $99.99 \%$ purity is selected as the injection gas. The inlet gas pressure is fixed at $10 \mathrm{~kg} / \mathrm{cm}^{2}$. The volume rate of injection gas was controlled using a MFC (Brooks 5850E) where the maximum output flow rate is $1000 \mathrm{ml} / \mathrm{min}$. The gas was injected at three volume rates $1000 \mathrm{ml} / \mathrm{min}(Q=100 \%), 600 \mathrm{ml} / \mathrm{min}(Q=$ $60 \%)$, and $200 \mathrm{ml} / \mathrm{min}(\mathrm{Q}=20 \%)$. The tube, which is made

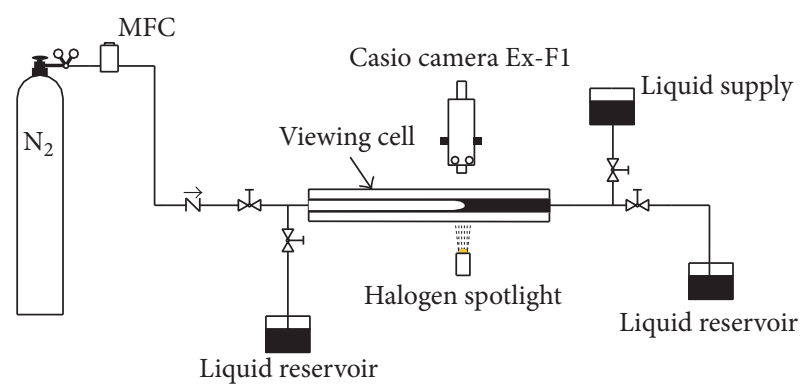

FIGURE 1: Experimental system.

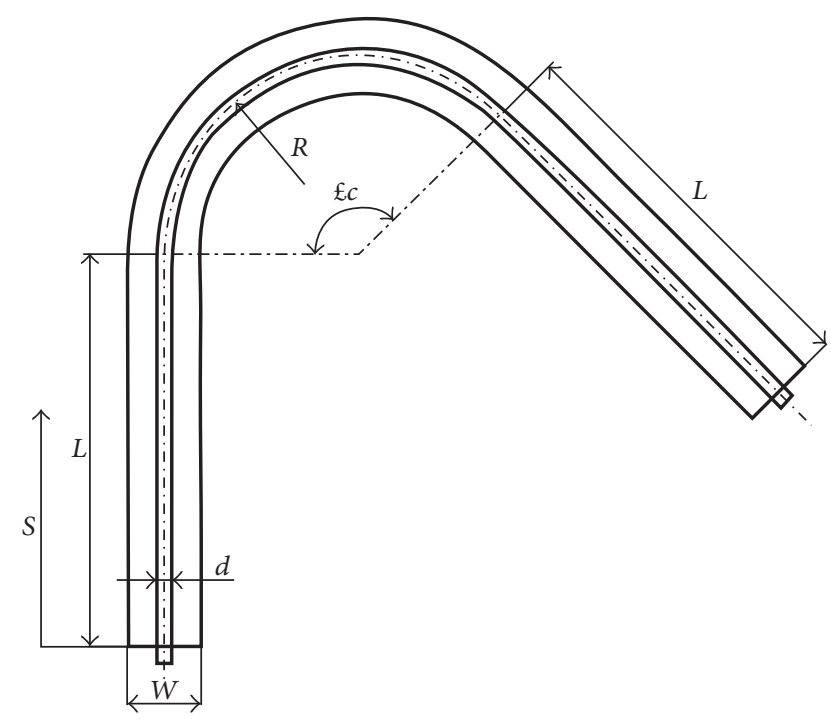

Figure 2: Schematic of the experimental tube.

of high-hardness heat-resistant glass, is shown in Figure 2. The dimensions of the tube are as follows: $L=800 \mathrm{~mm}, R=$ $400 \mathrm{~mm}, S$ represent measuring position, $W=50 \mathrm{~mm}$, and $d$ $=8 \mathrm{~mm}$. The curve angle $\theta$ are $90^{\circ}, 135^{\circ}$ and $180^{\circ}$, respectively. The tube was covered by a viewing box dimensions $50 \mathrm{~mm}$ $\times 50 \mathrm{~mm}$. Glycerin has similar refraction index to that of the glass. A ruler was fixed to the frame for convenience of calculation of the velocity of the bubbles.

2.2. Test Fluids. This work uses viscoelastic fluid. The viscoelastic fluids are $1.5 \mathrm{wt} \%$ and $0.5 \mathrm{wt} \%$ (carboxymethyl (CMC), polyacrylamide (PAA), and polyacryl sodium (PAS)). The suppliers of the three substances are Chung Yuan Chemicals Incorporation in Taiwan R.O.C. CMC chemical formula is $\mathrm{CH}_{2} \mathrm{CO}_{2} \mathrm{H}$, which is a powder-like substance, nontoxic, and easy to dissolve in water, but insoluble in organic solvents and dissolved into a viscous liquid; viscosity will rise due to temperature decline. PAA chemical formula is $\mathrm{CH}_{2} \mathrm{CHCONH}_{2}$, which have low concentration of high viscosity characteristics owing to the intermolecular friction; viscosity decreased with the temperature rise. PAS chemical formula is $\mathrm{C}_{3} \mathrm{H}_{3} \mathrm{NaO}_{2}$, which is dissolved in water, glycerol, propylene glycol, and other media, and has the temperature stability. With the role of fixed metal ions, it can prevent the negative effects of metal ions on the product and is a variety 
TABLE 1: Parameters of the Carreau-Yasuda viscosity model for the studied solutions.

\begin{tabular}{lcccccccc}
\hline Solution & $T\left({ }^{\circ} \mathrm{C}\right)$ & $\eta_{0}(\mathrm{Pas})$ & $\eta_{\infty}(\mathrm{Pas})$ & $\lambda(\mathrm{s})$ & $a_{1}$ & $a_{2}$ & $\dot{\gamma}\left(\mathrm{s}^{-1}\right)$ & Average error $(\%)$ \\
\hline $1.5 \%$ CMC & 25 & 2.895 & 0.0719 & 0.2999 & 0.8695 & 0.4199 & $0.1-3000$ & 3.50 \\
$0.5 \%$ CMC & 25 & 0.232 & 0.0183 & 0.0002 & 0.1908 & 0.1404 & $0.1-3000$ & 0.79 \\
$1.5 \%$ PAA & 25 & 31.530 & 0.0476 & 7.709 & 75.6511 & 0.2149 & $0.1-1000$ & 1.49 \\
$0.5 \%$ PAA & 25 & 3.902 & 0.0153 & 6.5964 & 8.2142 & 0.3479 & $0.1-1000$ & 1.52 \\
$1.5 \%$ PAS & 25 & 19.410 & 0.0532 & 5.9270 & 7.5677 & 0.2550 & $0.1-1000$ & 5.46 \\
$0.5 \%$ PAS & 25 & 2.150 & 0.0249 & 4.7794 & 5.1828 & 0.1332 & $0.1-1000$ & 1.03 \\
\hline
\end{tabular}

TABLE 2: Physical properties of viscoelastic fluids.

\begin{tabular}{lccc}
\hline Solution & $T\left({ }^{\circ} \mathrm{C}\right)$ & Density $\rho\left(\mathrm{kg} / \mathrm{cm}^{3}\right)$ & Surface tension $\sigma(\mathrm{mN} / \mathrm{m})$ \\
\hline 1.5 wt\% CMC in water & 25 & 1004.07 & 73.7 \\
0.5 wt $\%$ CMC in water & 25 & 945.07 & 73.3 \\
1.5 wt\% PAA in water & 25 & 1008.87 & 73.0 \\
0.5 wt\% PAA in water & 25 & 989.03 & 71.0 \\
1.5 wt $\%$ PAS in water & 25 & 998.67 & 74.4 \\
0.5 wt $\%$ PAS in water & 25 & 991.83 & 69.1 \\
\hline
\end{tabular}

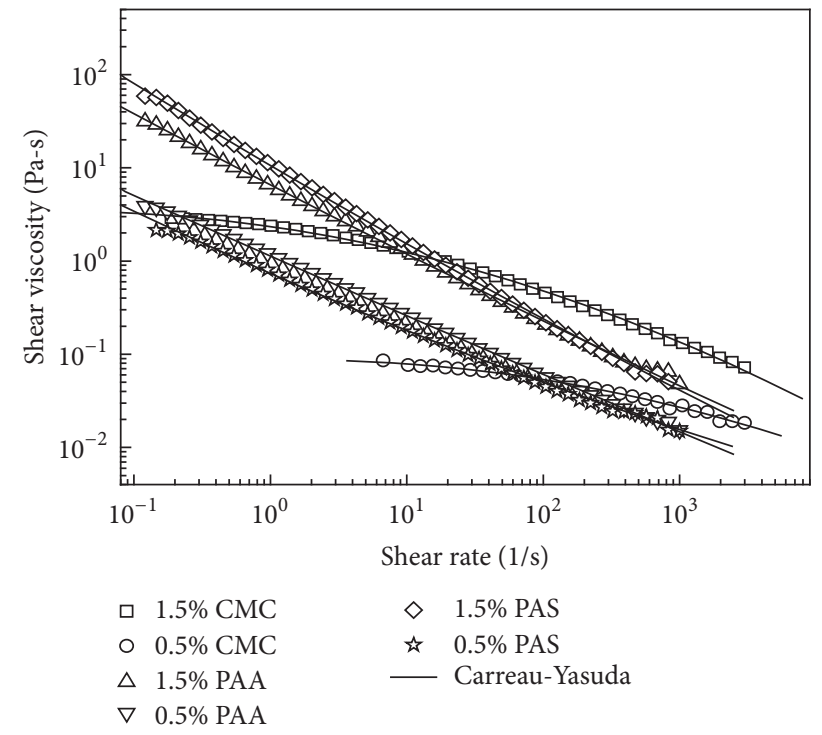

FIgURE 3: The shear viscosity as a function of the shear rate for the studied solutions and Carreau-Yasuda model fitted curves.

of special properties of the surface active agent. These three fluids are water-soluble polymer compounds, characterized by the fluid strain rate and shear stress into a nonlinear relationship.

Rheological measurements were carried out with a coneplate type rheometer (Gemini HR nano). The measurements of rheological properties were carried out at $25^{\circ} \mathrm{C}$, which is the same temperature condition for the gas penetration experiments. All the viscoelastic fluids have shear-thinning viscosity and nonzero first normal stress difference. The shear viscosity of every viscoelastic fluid shows strong shearthinning property. The solutions exhibited shear-thinning behavior as can be seen in the viscosity-shear rate plot of Figure 3. The Carreau-Yasuda viscosity model (1) was fitted

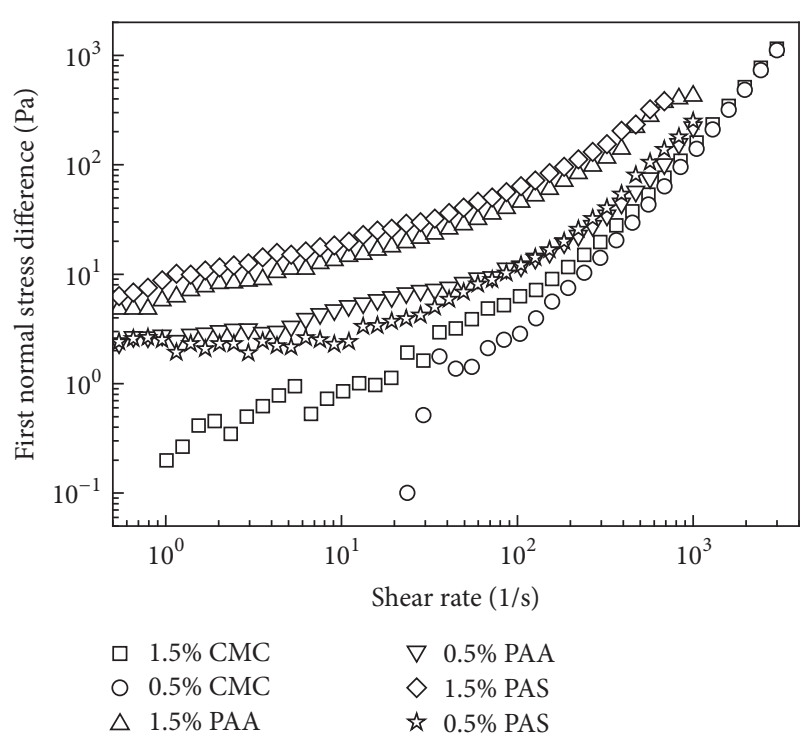

FIGURE 4: The first normal stress difference as a function of the shear rate for the studied solutions.

to the data and the fittings are represented in the figure by the full lines. Their parameters can be found in Table 1 .

$$
\mu=\mu_{\infty}+\left(\mu_{0}-\mu_{\infty}\right)\left(1+(\lambda \dot{\gamma})^{a}\right)^{(n-1) / a},
$$

where $\mu$ is the measured viscosity, $\dot{\gamma}$ is the applied shear rate, $\mu_{0}$ is the viscosity limit when $\dot{\gamma} \rightarrow 0$, and $\mu_{\infty}$ is the viscosity at infinite shear rate, which was set as the solvent viscosity. The parameter $\lambda$ has units of time and $n$ and $a$ are dimensionless parameters described in Sousa et al. [11]. Figure 4 shows the shear rate and the first normal stress difference of the test fluids. Table 2 summarizes both surface tensions and the density $\rho$ of the test fluids at $25^{\circ} \mathrm{C}$. The surface tension was measured with a Du Nouy (DST30) and the density $\rho$ was measured with (DA-130N). 


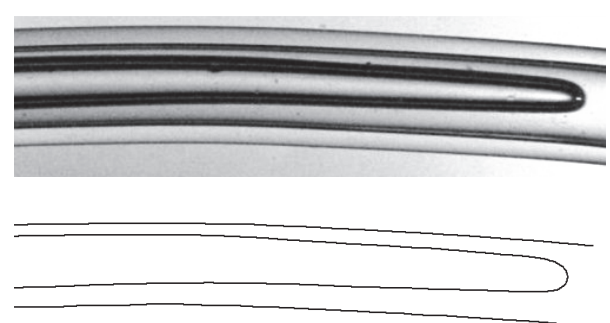

FIGURE 5: Bubbles image before and after processing.

2.3. Experimental Method. In this experiment, the gas is injected into tube filled with various viscoelastic fluids in an isothermal environment. The volume rate of the injection gas was controlled by MFC in this experiment. The profile of the bubble is captured by a high-speed camera. Figure 5 shows a photo before the image processing and the ultimate graphics generated by the image processing. The width of the bubble was estimated by these images.

In this work use the image processing software PhotoCap as the basis of the image after treatment. In this work, we research the impact of the various flow rates and various viscoelastic fluids on the bubble velocity $(U)$ and the dimensionless parameters, such as the capillary number $(\mathrm{Ca})$, Weissenberg number (Wi), and dimensionless parameter $R$.

In this work, runner channel shape is curved tube and labeled scale in the box. The total lengths of the flow path are different. The length of $90^{\circ}$ curved tube is $230 \mathrm{~cm}$ and the shooting range is $0 \sim 220 \mathrm{~cm}$. The length of $135^{\circ}$ curved tube is $253 \mathrm{~cm}$ and the shooting range is $0 \sim 240 \mathrm{~cm}$. The length of $180^{\circ}$ curved tube is $293 \mathrm{~cm}$ and the shooting range is $0 \sim$ $270 \mathrm{~cm}$. Shooting the whole image of the bubbles has its degree of difficulty, so we shoot each segment taking $10 \mathrm{~cm}$ and repeating three times in this research. Passing time can be obtained from every 1/60 of a second difference between the two images. The average of three speed values get an average of instantaneous velocity in that bubble zone, which is defined as velocity of each segment.

The dimensionless parameters are defined as [10]

$$
\begin{aligned}
\mathrm{Ca} & =\frac{\eta(\dot{\gamma}) U}{\sigma}, \\
R & =\frac{N_{1}}{2 \eta \dot{\gamma}^{2}}, \\
\mathrm{Wi} & =\frac{R U}{H},
\end{aligned}
$$

where $U$ is the average velocity of the bubble, $\eta(\dot{\gamma})$ is the shear viscosity of the viscoelastic fluids, $\sigma$ is the surface tension of the viscoelastic fluids, $\dot{\gamma}$ is shear rate, $\rho$ is the density of the viscoelastic fluids, $R$ is the Maxwell type relaxation time, $N_{1}$ is the first normal stress difference, and $H$ is cure tube representative length. We need to determine a representative shear rate $\dot{\gamma}=U / H$ to evaluate $\eta(\dot{\gamma})$ and $R$.

\section{Results and Discussion}

3.1. Bubble Velocity. In this work, there are long bubble velocity variations within the different curved tube. Three

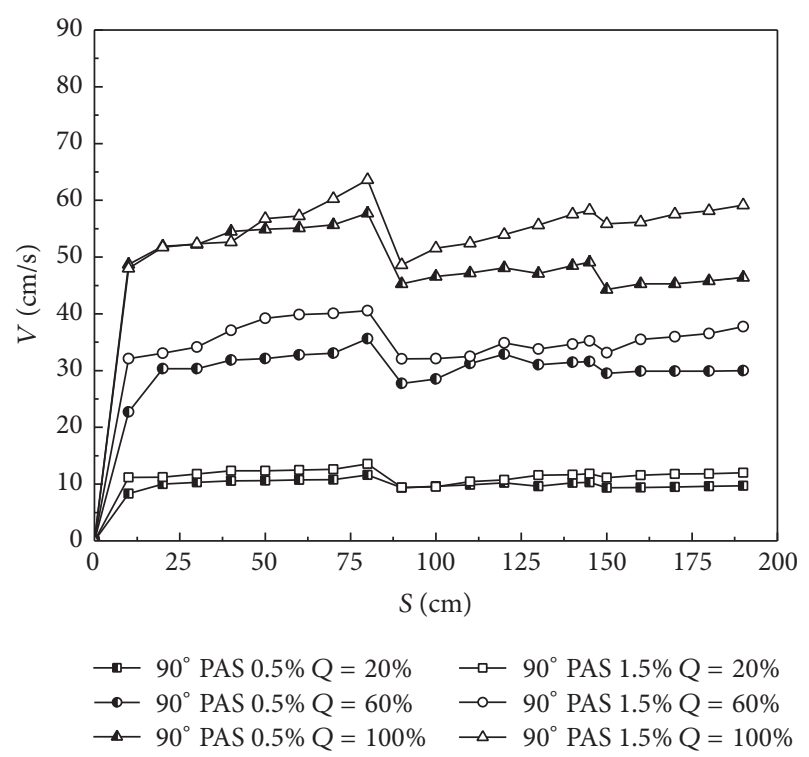

FIGURE 6: The PAS velocity-position diagram of various flow in $90^{\circ}$ curved tube.

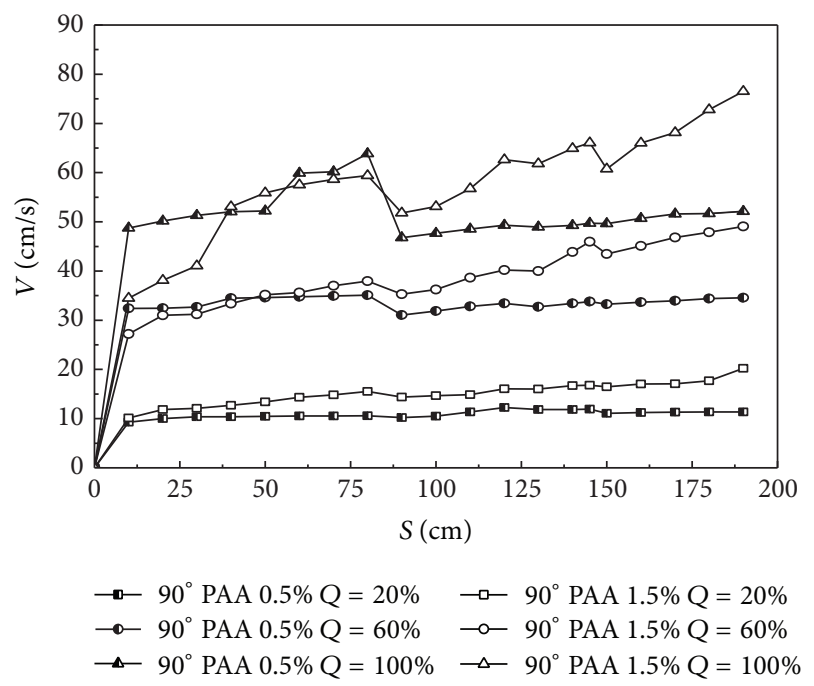

FIGURE 7: The PAA velocity-position diagram of various flow in $90^{\circ}$ curved tube.

kinds of curved tube can be divided into four sections for analysis individually. In $90^{\circ}$ curved tube, the first section is $0 \mathrm{~cm}$ to $80 \mathrm{~cm}$ where the velocity is progressively increased, the second section is $80 \mathrm{~cm}$ to $120 \mathrm{~cm}$ where the bubbles begin to enter the tube, and the experiment found just from straight tube into the curved tube $(80 \mathrm{~cm}$ to $90 \mathrm{~cm})$ rate decreased slightly; afterwards the rate began to increase at the location $110 \mathrm{~cm}$ to $120 \mathrm{~cm}$ about at 45 degree; the third section is $120 \mathrm{~cm}$ to $145 \mathrm{~cm}$ in which the rate decreased slightly $(120 \mathrm{~cm}$ to $130 \mathrm{~cm}$ ) and then the speed increased again until the end of the curved tube $(145 \mathrm{~cm})$; the fourth section is $145 \mathrm{~cm}$ to $190 \mathrm{~cm}$ in which the rate decreased slightly $(145 \mathrm{~cm}$ to $150 \mathrm{~cm})$ and then progressively increases until export. The variation of bubble velocity in $90^{\circ}$ curved tube is shown in Figures 6-8.

In $135^{\circ}$ curved tube, the first section is $0 \mathrm{~cm}$ to $80 \mathrm{~cm}$ where the velocity is progressively increased, the second 


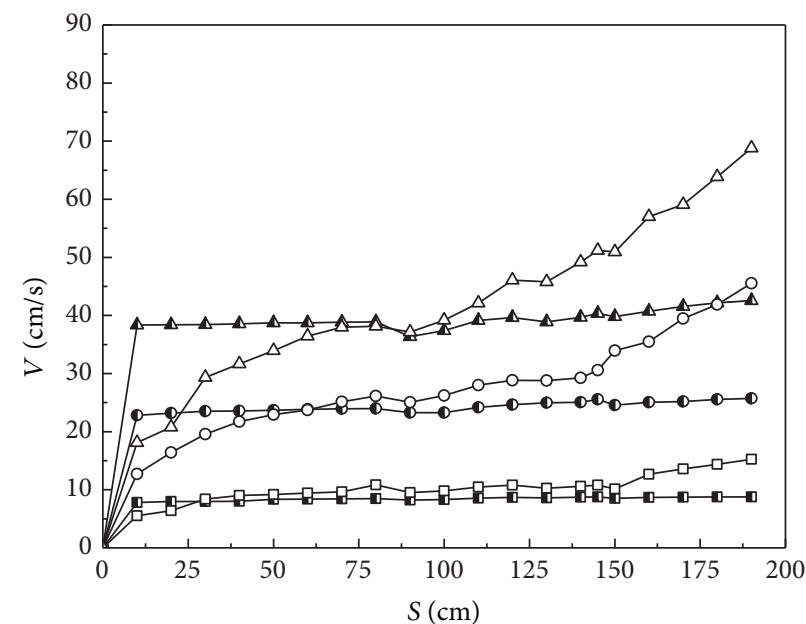

$$
\begin{aligned}
& \rightarrow-90^{\circ} \mathrm{CMC} 0.5 \% \mathrm{Q}=20 \% \rightarrow 90^{\circ} \mathrm{CMC} 1.5 \% \mathrm{Q}=20 \% \\
& \rightarrow-90^{\circ} \mathrm{CMC} 0.5 \% \mathrm{Q}=60 \% \multimap 90^{\circ} \mathrm{CMC} 1.5 \% \mathrm{Q}=60 \% \\
& \triangle 90^{\circ} \mathrm{CMC} 0.5 \% \mathrm{Q}=100 \% \multimap 90^{\circ} \mathrm{CMC} 1.5 \% \mathrm{Q}=100 \%
\end{aligned}
$$

FIGURE 8: The CMC velocity-position diagram of various flow in $90^{\circ}$ curved tube.

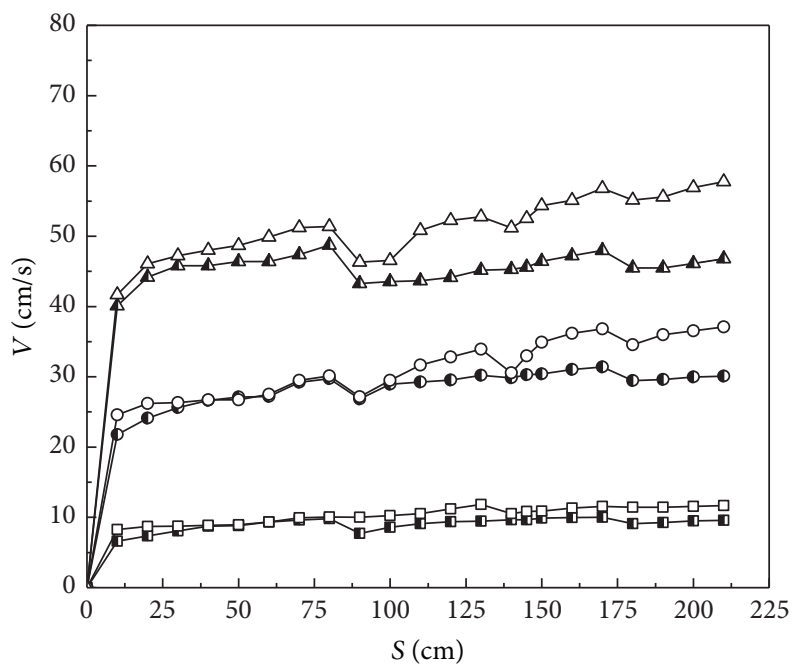

$$
\begin{aligned}
& \rightarrow-135^{\circ} \text { PAS } 0.5 \% Q=20 \% \rightarrow-135^{\circ} \text { PAS } 1.5 \% Q=20 \% \\
& \rightarrow 135^{\circ} \text { PAS } 0.5 \% Q=60 \% \multimap 135^{\circ} \text { PAS } 1.5 \% Q=60 \% \\
& \triangle 135^{\circ} \text { PAS } 0.5 \% \mathrm{Q}=100 \% \multimap 135^{\circ} \text { PAS } 1.5 \% \mathrm{Q}=100 \%
\end{aligned}
$$

FIGURE 9: The PAS velocity-position diagram of various flow in $135^{\circ}$ curved tube.

section is $80 \mathrm{~cm}$ to $130 \mathrm{~cm}$ where the bubbles begin to enter the tube and then the velocity is progressively increased about at $120 \mathrm{~cm}$ to $130 \mathrm{~cm}$ section; the third section is $130 \mathrm{~cm}$ to $177 \mathrm{~cm}$ in which the rate decreased slightly $(120 \mathrm{~cm}$ to $130 \mathrm{~cm}$ ) at the bubble through 67.5 degrees and then the speed increased again until the end of the curved tube $(177 \mathrm{~cm})$; the fourth section is $177 \mathrm{~cm}$ to $220 \mathrm{~cm}$ in which the rate decreased slightly $(177 \mathrm{~cm}$ to $180 \mathrm{~cm})$ as the bubble flow from curved tube end into straight tube end and then progressively increases until export. The variation of bubble velocity in $135^{\circ}$ curved tube is shown in Figures 9-11.

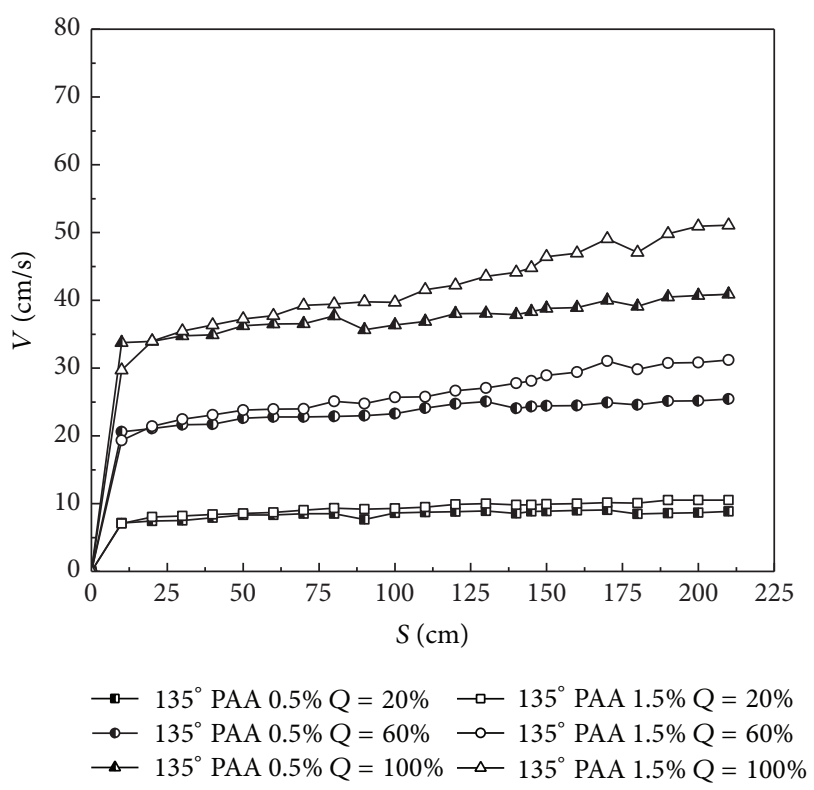

FIGURE 10: The PAA velocity-position diagram of various flow in $135^{\circ}$ curved tube.

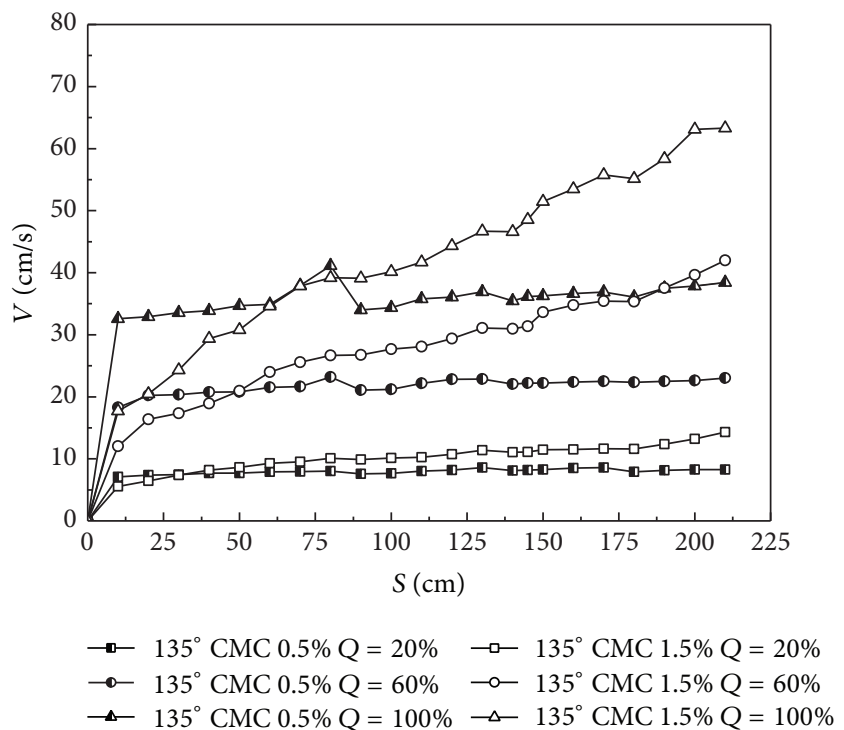

FIGURE 11: The CMC velocity-position diagram of various flow in $135^{\circ}$ curved tube.

In $180^{\circ}$ curved tube, the first section is $0 \mathrm{~cm}$ to $80 \mathrm{~cm}$ where the velocity is progressively increased; the second section is $80 \mathrm{~cm}$ to $150 \mathrm{~cm}$ in which the rate decreased slightly $(177 \mathrm{~cm}$ to $180 \mathrm{~cm})$ as the bubble from straight tube end into curved tube end and then progressively increase until $140 \mathrm{~cm}$ to $150 \mathrm{~cm}$ where the bubbles begin to enter the tube and then the velocity is progressively increased about $120 \mathrm{~cm}$ to $130 \mathrm{~cm}$ stage, the third section is $150 \mathrm{~cm}$ to $210 \mathrm{~cm}$ in which the rate decreased slightly $(120 \mathrm{~cm} \sim 130 \mathrm{~cm})$ as the bubble through 90 degrees curved tube and then the speed increased again until the end of the curved tube $(210 \mathrm{~cm})$, and the fourth section is $210 \mathrm{~cm}$ to $270 \mathrm{~cm}$ where the rate decreased slightly 


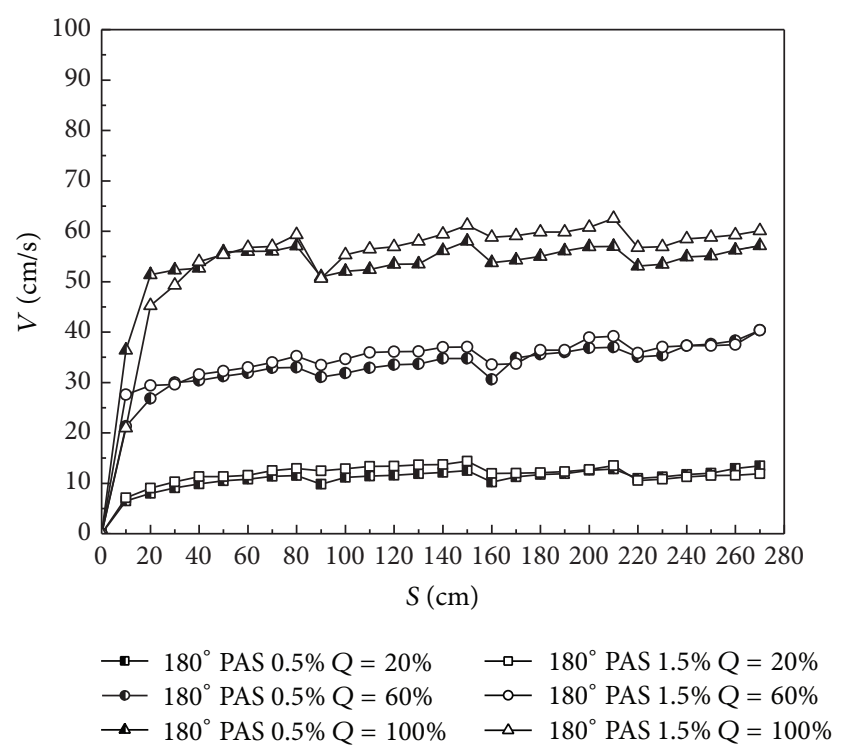

FIGURE 12: The PAS velocity-position diagram of various flow in $180^{\circ}$ curved tube.

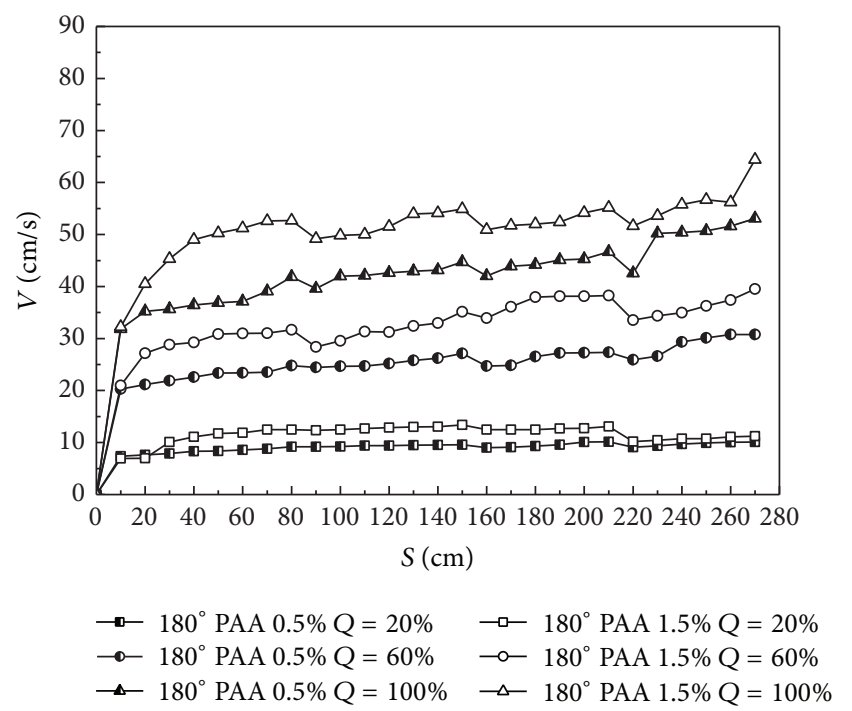

FIgURE 13: The PAA velocity-position diagram of various flow in $180^{\circ}$ curved tube.

in its junction $(210 \mathrm{~cm} \sim 220 \mathrm{~cm})$ as the bubble flow from curved tube end into straight tube end and then progressively increase until export. The variation of bubble velocity in $180^{\circ}$ curved tube is shown in Figures 12-14.

The change degree of bubble velocities varies by fluid concentrations. At the same curved tube angle and gas flow rate, the higher concentration has the faster velocity in the same fluid; the results and that of Cheng-Hsing Hsu et al. [15] are the same. The reason is that the higher fluid concentration resulting in bubble development is limited such that the leading edge of the bubble is squeezed, so the bubble diameter getting smaller made bubble velocity along faster.

In the speed error aspect, relative mean errors of three experiments of $90^{\circ}, 135^{\circ}$, and $180^{\circ}$ curved tube are $1.01 \%$,

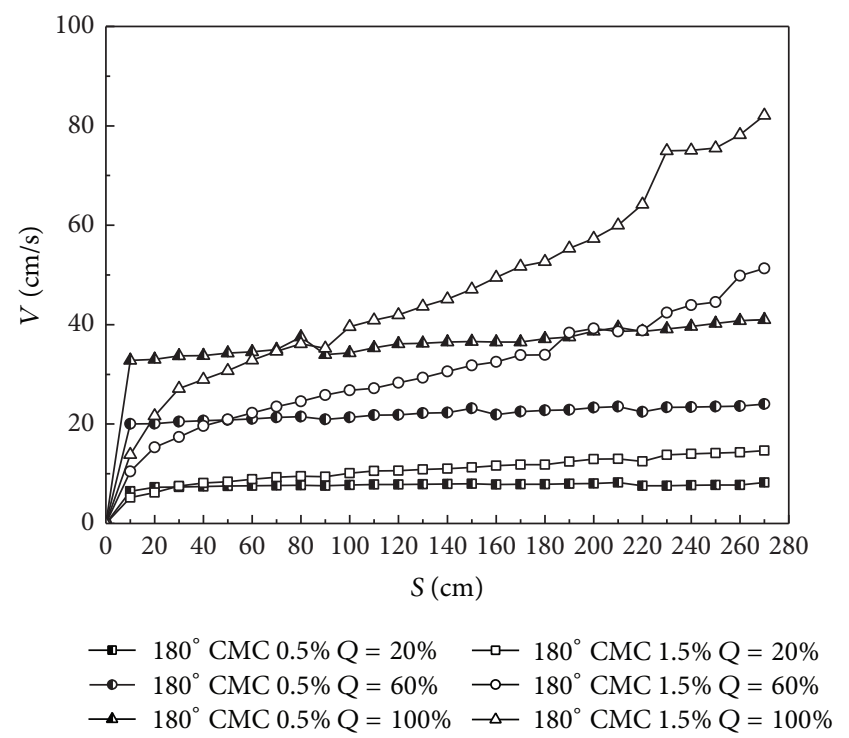

FIgURE 14: The CMC velocity-position diagram of various flow in $180^{\circ}$ curved tube.

$0.62 \%$, and $0.63 \%$, respectively, and the maximum relative errors are $5.0 \%, 3.9 \%$, and $4.4 \%$, respectively.

According to theory, however, 80 to $90 \mathrm{~cm}$ section of straight tube (curved tube $0^{\circ}$ ) with the speed should be the same with the end of the three curved tube $\left(90^{\circ}, 135^{\circ}\right.$, and $180^{\circ}$ ). However, the present result is not so; this inquiry is because the exit end of the experiment does not have a damping mechanism as a buffer but is directly connected to the atmospheric pressure and the gas in the tube-driven fluid which required less and less resistance decreases case under the cause of bubbles through the apex of curved tube, after the speed has not decreased but increased. Comparison with the velocity change of the long bubble in curve tube, straight tube [15], and suddenly contracting and expanding tube [16]; these results show that when the gas flow rate is fixed, the fluid viscosity is bigger and the bubbles moves faster in the tube.

\subsection{The Analysis of the Bubble in Equal Diameter Position.} According to past experiments, the bubbles want to investigate the rate of change in the hollow straight tube when the tube is taken at 1.5 times the diameter of the bubbles from the tip, because it rapidly approaches parallel on both sides of the outer edge of the bubble [2]. This experiment is to investigate the case of the bubble in the curved tube; the 1.5 times value of the experience in straight tube is not applicable. It must be found within a bubble developing in the curved tube where its width tends to have a constant value. First, the coordinate system of the software PhotoCap is set to Pixel units and then loading image to software, in which case the screen can display the image at any point in the coordinate position. follows.

Image processing sequences of this experiment are as Step 1. Load original image into software as shown in Figure 15.

Step 2. Detect boundary as shown in Figure 16. 


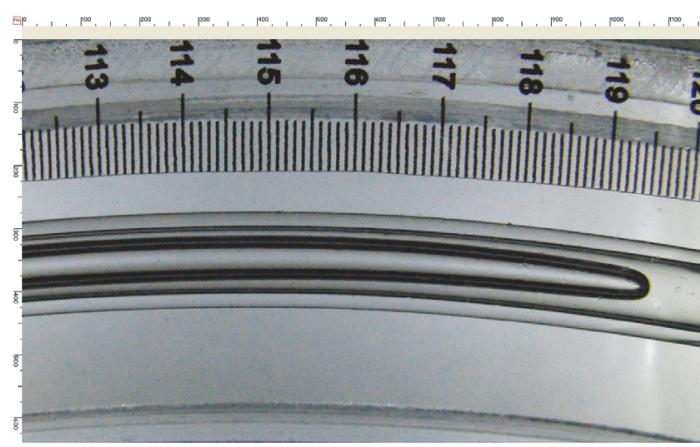

FIGURE 15: The original image loading software.

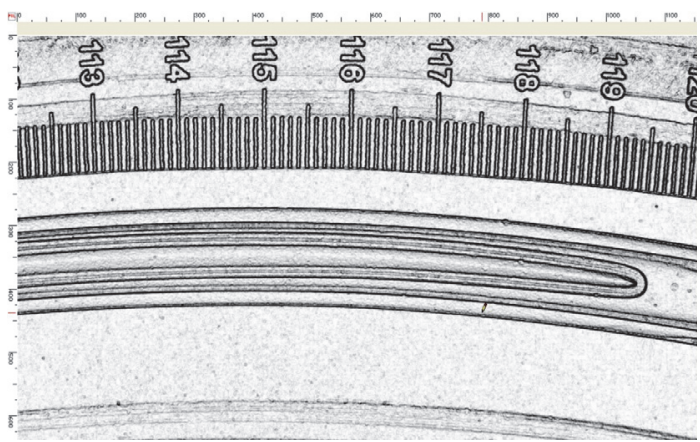

FIgURE 16: Boundary detection.

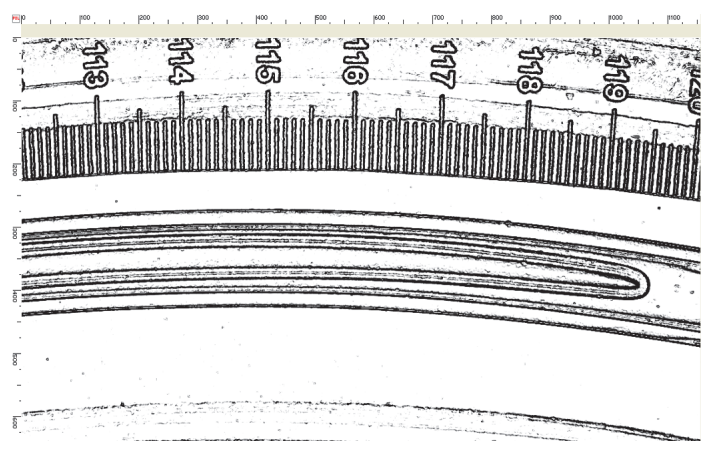

FIgURE 17: Contrast adjustment.

Step 3. Adjust contrast as shown in Figure 17.

Step 4. Enlarge image as shown in Figure 18.

It must first confirm the same thickness of up and down the wall to avoid errors when shooting in Step 4. To use the inner diameter converse to get the relationship between the pixel unit and mm, 1 pixel is approximately equal to $0.038 \mathrm{~mm}$. In this work, the analysis of the image assumed that each adjacent pixel of curved tube is parallel. Fixing the $x$-axis values can get the bubbles width for required analysis. Spacing 100 pixel measured the bubble width once. If the bubble in three successive intervals gap within 1 Pixel, they use approximation looking back close to the constant
TABLE 3: The multiples of the diameter from the tip width of the long bubbles approached to a constant value.

\begin{tabular}{llll}
\hline & $90^{\circ}$ & $135^{\circ}$ & $180^{\circ}$ \\
\hline PAS0.5\% 20\% & 1.63 & 2.50 & 3.88 \\
PAS0.5\% 60\% & 2.50 & 3.63 & 4.10 \\
PAS0.5\% 100\% & 3.88 & 4.25 & 5.50 \\
PAS1.5\% 20\% & 2.37 & 2.75 & 3.75 \\
PAS1.5\% 60\% & 3.13 & 3.50 & 4.50 \\
PAS1.5\% 100\% & 4.25 & 4.88 & 5.13 \\
PAA1.5\% 20\% & 1.75 & 3.61 & 4.50 \\
PAA1.5\% 60\% & 3.25 & 3.84 & 4.88 \\
PAA1.5\% 100\% & 4.46 & 4.75 & 5.96 \\
CMC1.5\% 20\% & 1.53 & 2.38 & 3.07 \\
CMC1.5\% 60\% & 2.51 & 2.63 & 3.25 \\
CMC1.5\% 100\% & 2.88 & 3.17 & 3.57 \\
\hline
\end{tabular}

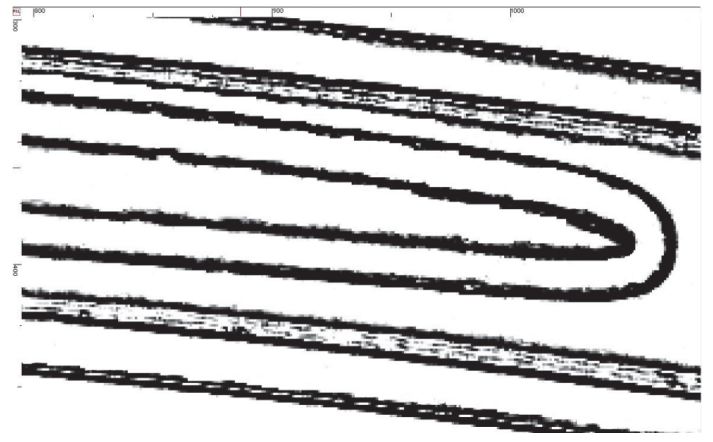

FIGURE 18: Zoom in picture.

starting value. The distance from starting point to bubble head divided by the diameter of tube is the desire to find multiple. In grayscale judgments, if the boundary grayscale value is less than 100 it is regarded as 0 (black) and more than 100 substituted 255 (white). However, judging boundary grayscale value needs experience to judge. The end of the experiment takes $100 \mathrm{~cm}-110 \mathrm{~cm}$ as grayscale judgments range. Required multiples after processing for each situation are shown in Table 3. Multiple changes from 1.53 times to 5.95 times, so this experiment fixes pipe diameters, which is six multiples from bubble head to analysis difference.

With different curved tube and solution concentration, multiple will change. Most of the cases has the same trends as follows:

(1) Under the same solution and concentration, the larger angle of curved tube has the greater multiples.

(2) Under the same angle of curved tube, the larger solution concentration has the greater multiples.

PhotoCap software samples nine kinds of conditions at random, and the percentage error of this experimental method compares with that of MATLAB process (a flow rate of $100 \%$, e.g.) within about $7 \%$ (the maximum relative error of $6.86 \%$; the minimum relative error of $0.7 \%$; on average $3.24 \%$ relative error). 


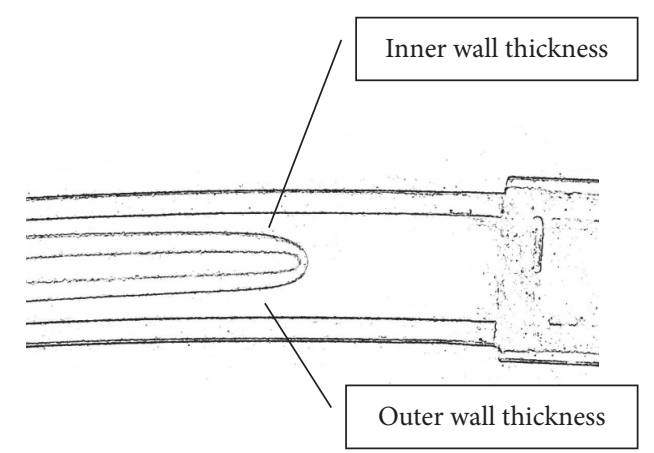

FIGURE 19: Difference is defined within the outer gap.

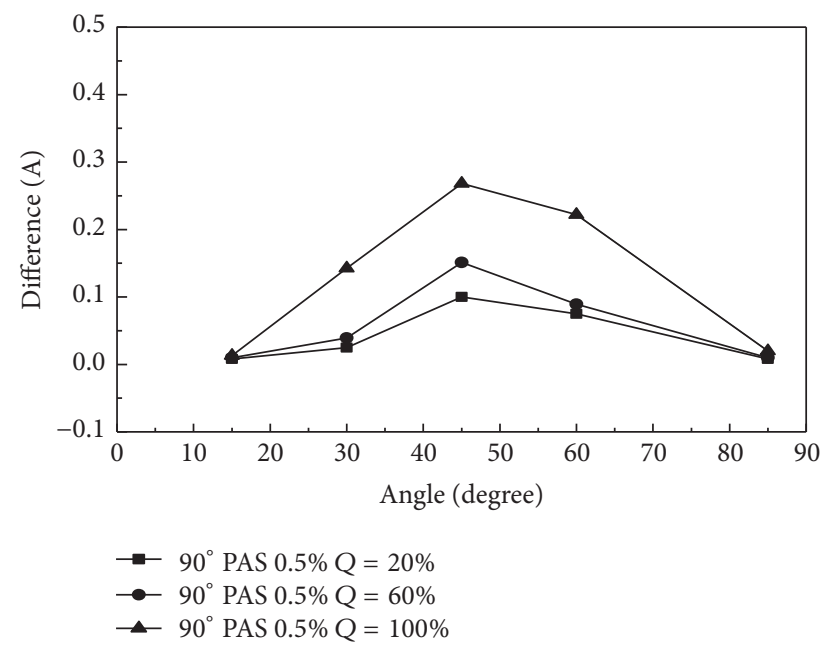

Figure 20: The PAS angle of curved tube: difference diagram of various flows in $90^{\circ}$ curved tube.

3.3. Difference. The difference formula is seen in Yang and Chou [9] as follows:

$$
A=\frac{(B-C)}{D}
$$

where $A$ is difference; $B$ is outer wall thickness; $C$ is inner wall thickness; and $D$ is average thickness. It gets a higher gas pressure which can reduce the extent of gas eccentricity and difference. Equation (3) can analyze the offset conditions of gas hollowed zone, and the greater difference has the greater eccentricity. When increasing the gas emptied eccentric resistance has smaller difference. The inner and outer wall thickness in this experiment are defined as shown in Figure 19. In this work, computational fluid difference takes PAS $0.5 \%$, PAS $1.0 \%$, PAS $1.5 \%$, and PAA $1.5 \%$ to analysis. The research measures, respectively, the values from the bubble wall inside and outside at the location six-diameter upstream from the bubbles front. To take $15^{\circ}, 30^{\circ}, 45^{\circ}, 60^{\circ}$, and $85^{\circ}$ in $90^{\circ}$ curved tube, $15^{\circ}, 30^{\circ}, 67.5^{\circ}, 90^{\circ}$, and $130^{\circ}$ in $135^{\circ}$ curved tube, and $15^{\circ}, 30^{\circ}, 60^{\circ}, 90^{\circ}, 120^{\circ}, 150^{\circ}$, and $175^{\circ}$ in $180^{\circ}$ curved tube calculate difference. From Figures $20-$ 28 it is found that the eccentricity variation trends have a

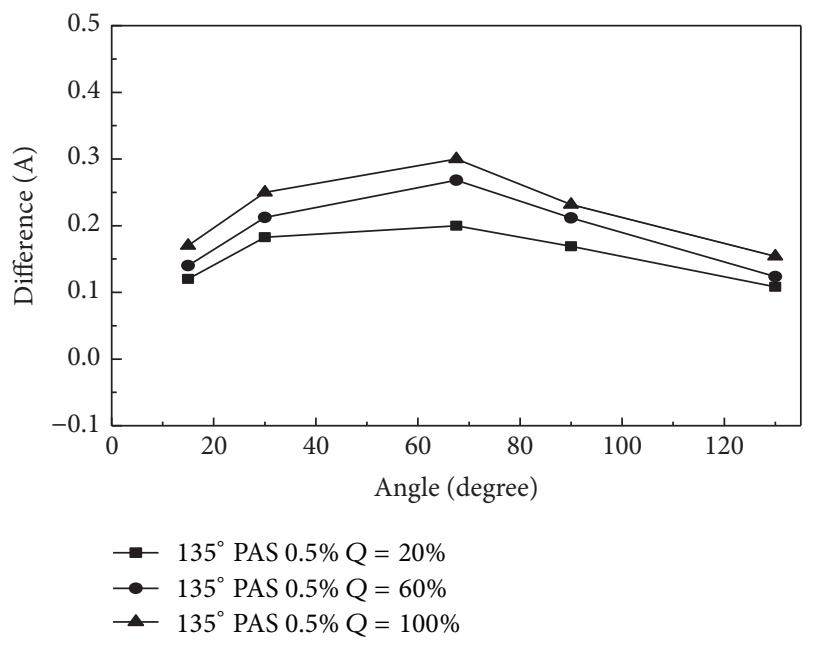

FIgURE 21: The PAS 0.5\% angle of curved tube: difference diagram of various flows in $135^{\circ}$ curved tube.

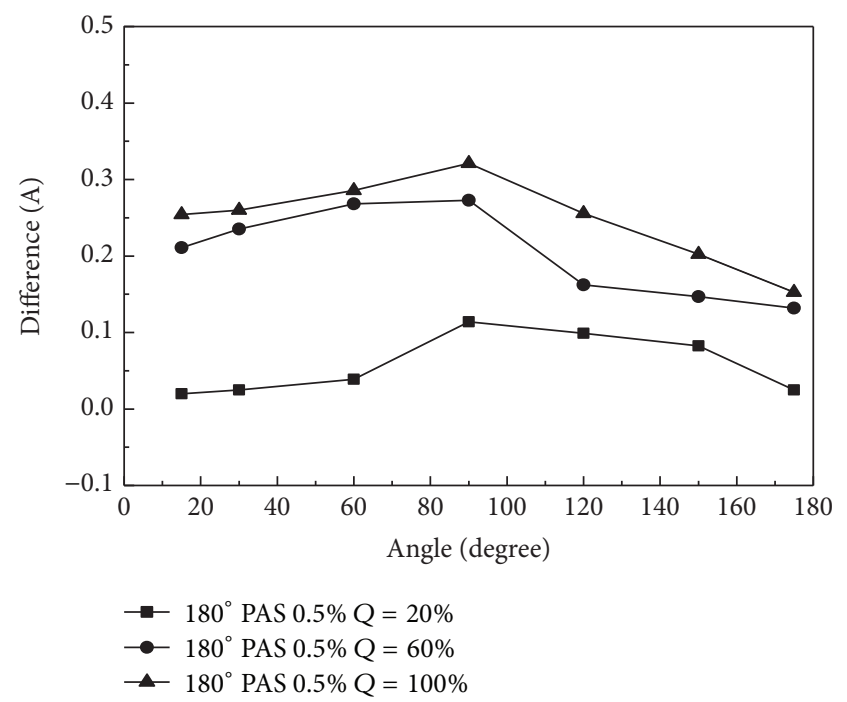

FIGURE 22: The PAS $0.5 \%$ angle of curved tube: difference diagram of various flows in $180^{\circ}$ curved tube.

significant relationship with the fluid flow and viscosity. In the same curved tube and viscosity of the fluid, higher flow has greater difference, and on the contrary lower flow has smaller difference. Investigating the causes, greater flow has faster velocity and greater kinetic energy of gas outward emptied fluid similar to the effect of centrifugal force. Therefore, larger flow has larger difference relatively. Lower velocity when flow is lower has smaller kinetic energy of gas outward emptied fluid. The bubbles difference will be smaller. Cheng-Hsing Hsu et al. [15] discussed fractional ratio of long bubble using silicone oil of different viscosity. Larger viscosity of silicone oil has higher fractional ratio where fractional convergence equals radius of circular tube minus radius of bubble all divided by radius of circular tube.

In this work, relatively the same fluid, but not at the same viscosity when the flow rate is fixed, has the greater 


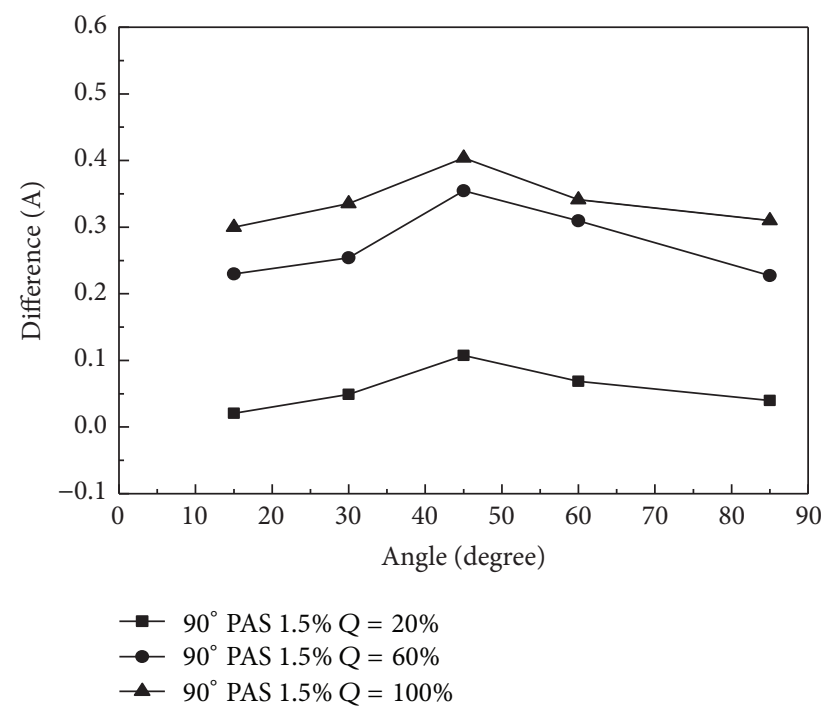

FIgURE 23: The PAS 1.5\% angle of curved tube: difference diagram of various flows in $135^{\circ}$ curved tube.

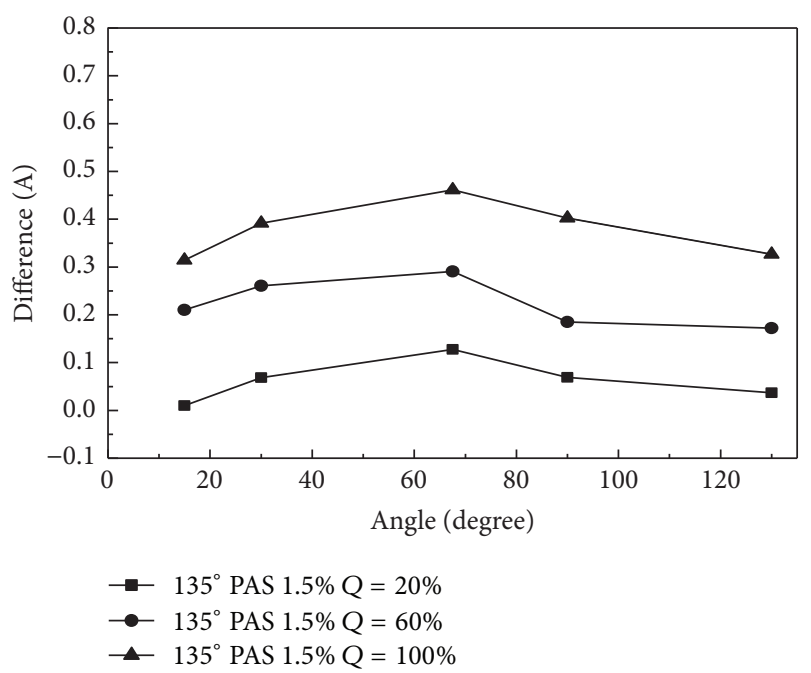

FIGURE 24: The PAS 1.5\% angle of curved tube: difference diagram of various flows in $135^{\circ}$ curved tube.

eccentricity when the viscosity is larger. The result is the same as Cheng-Hsing Hsu et al. [15]. Investigating the causes, greater fluid viscosity limits the development of long bubbles, so the bubble front is smaller which make the gap larger inside and outside and the eccentricity also increases. It was found that maximum difference which is $45^{\circ}, 67.5^{\circ}$, and $90^{\circ}$ is in the middle of angle in the $90^{\circ}, 135^{\circ}$, and $180^{\circ}$ curved tube.

The reason is that curved tube curvature becomes large in bubble forming process when flowing from straight tube into curved tube, and bubble front develop into elongated bubble. Outer wall thickness becomes larger, and thus also followed eccentricity becomes larger. In the difference error aspect, the relative mean errors of three experiments of $90^{\circ}, 135^{\circ}$, and $180^{\circ}$ curved tube are $0.38 \%, 0.53 \%$, and $0.51 \%$, respectively,

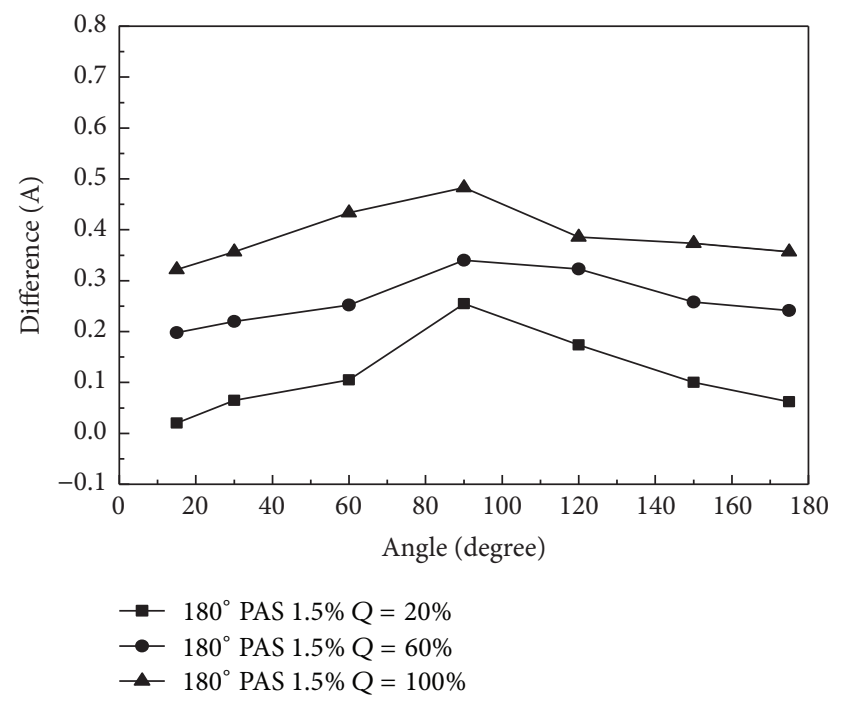

FIGURE 25: The PAS 1.5\% angle of curved tube: difference diagram of various flows in $180^{\circ}$ curved tube.

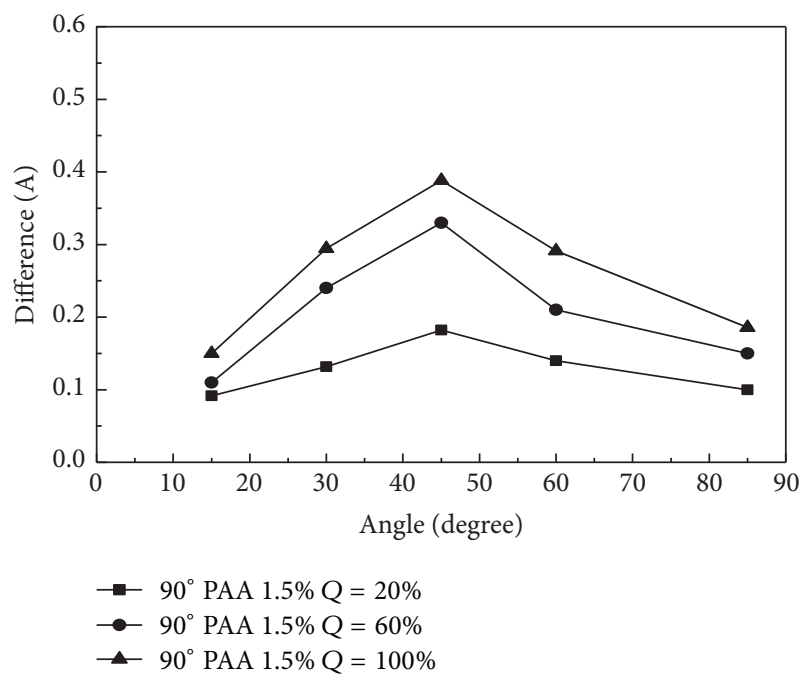

FIgure 26: The PAA 1.5\% angle of curved tube: difference diagram of various flows in $90^{\circ}$ curved tube.

and the maximum relative errors are $0.89 \%, 1.09 \%$, and $1.10 \%$, respectively.

3.4. Ca and Wi. Using PAS 1.5\%, PAA $1.5 \%$, and PAS $0.5 \%$ fluid and taking $90^{\circ}$ position discuss the relationships of Wi and $\mathrm{Ca}$ with difference. Figure 29 shows the case when larger $\mathrm{Ca}$ has larger bubble difference. Figure 30 shows the case when larger Wi has larger bubble difference. The relationship between $\mathrm{Ca}$ and Wi with difference is proportional. The viscoelastic fluids shear viscosity increases when the bubble speed drops, resulting in increased resistance to gas emptied eccentric; the difference is reduced. The viscoelastic fluids shear viscosity drops when the bubble speed increases, resulting in reduced resistance to gas emptied eccentric; the difference is increased. 


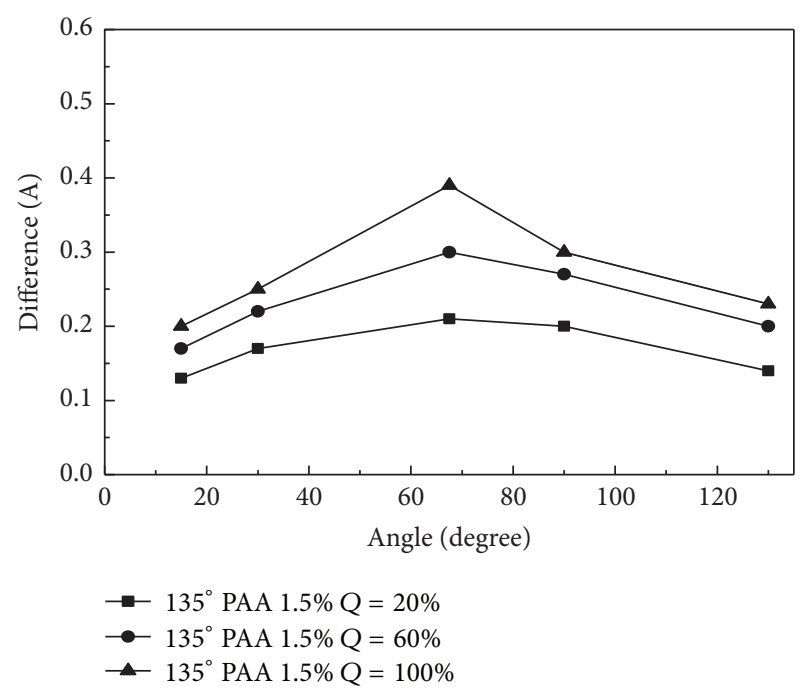

Figure 27: The PAA 1.5\% angle of curved tube: difference diagram of various flows in $135^{\circ}$ curved tube.

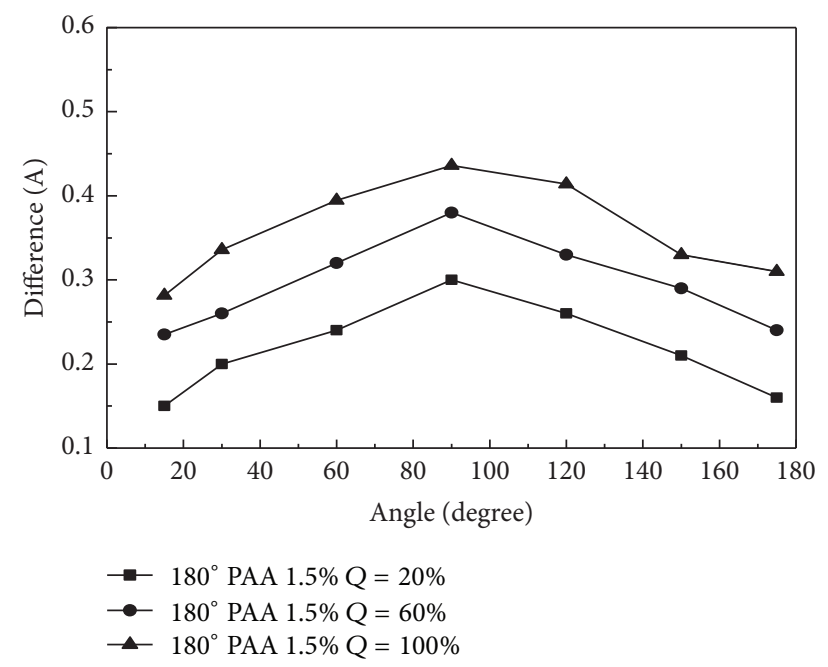

Figure 28: The PAA 1.5\% angle of curved tube: difference diagram of various flows in $180^{\circ}$ curved tube.

\section{Conclusions}

In this experiment using viscoelastic fluids and the experimental results obtained at six times the diameter of the bubble of the pipe, the diameter of the bubbles will tend to constant. When the gas flow rate is fixed, the shear viscosity is greater and the relative speed of the bubble is larger. Outlet end directly connected to the atmospheric pressure will push the fluid resistance getting smaller, so that the back end speed of the elbow is not decreased but increased.

In the curved tube angle corresponds to the difference aspect, when the viscosity of the fluid is the same, the flow is higher and its difference will be greater; on the contrary the lower the flow, the smaller the difference. Capillary number

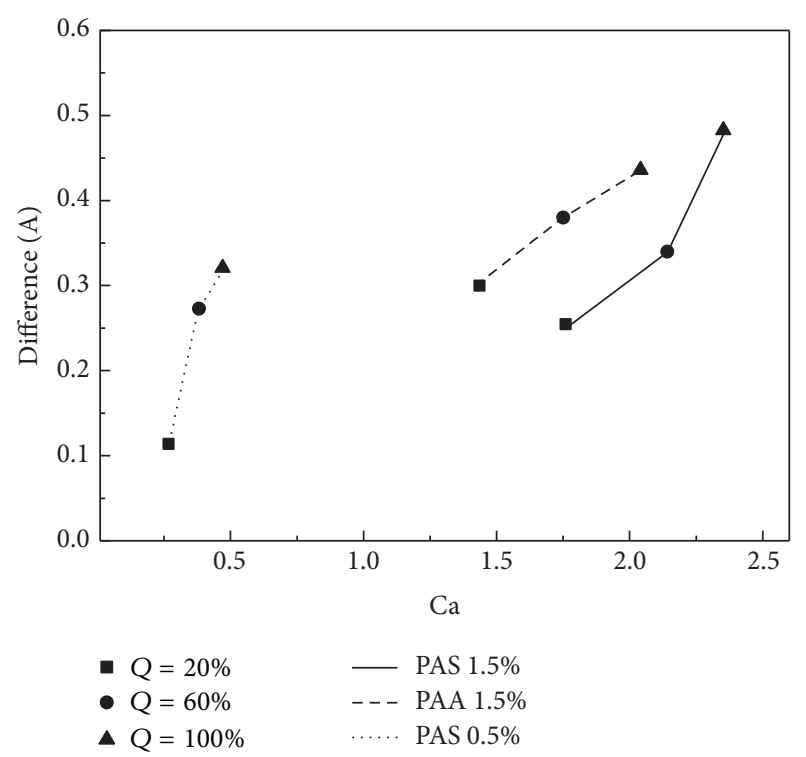

FIGURE 29: The PAS capillary number: difference diagram of various flows in $180^{\circ}$ curved tube.

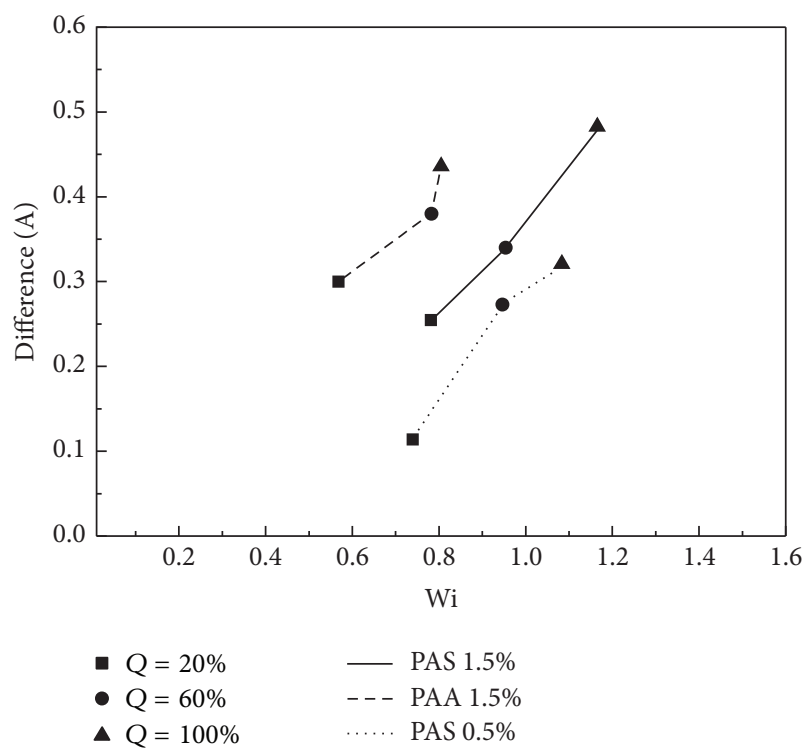

FIgURE 30: The PAS Weissenberg number: difference diagram of various flows in $180^{\circ}$ curved tube.

and Weissenberg number are proportional to the difference of bubbles in the tip of the curved tube.

\section{Competing Interests}

The author declares that they have no competing interests.

\section{References}

[1] P. G. Saffman and G. Taylor, "The penetration of a fluid into a porous medium or Hele-Shaw cell containing a more viscous liquid," Proceedings of the Royal SocietyA-Mathematical, Physical and Engineering Sciences, vol. 245, pp. 312-329, 1958. 
[2] G. I. Taylor, "Deposition of a viscous fluid on the wall of a tube," Journal of Fluid Mechanics, vol. 10, no. 2, pp. 161-165, 1961.

[3] W. B. Kolb and R. L. Cerro, "Coating the inside of a capillary of square cross section," Chemical Engineering Science, vol. 46, no. 9, pp. 2181-2195, 1991.

[4] H. B. Wong, C. J. Radke, and S. Morris, "The motion of long bubbles in polygonal capillaries. Part 1. Thin films," Journal of Fluid Mechanics, vol. 292, pp. 71-94, 1995.

[5] H. Wong, C. J. Radke, and S. Morris, "The motion of long bubbles in polygonal capillaries. Part 2. Drag, fluid pressure and fluid flow," Journal of Fluid Mechanics, vol. 292, pp. 95-110, 1995.

[6] P. C. Huzyak and K. W. Koelling, "The penetration of a long bubble through a viscoelastic fluid in a tube," Journal of NonNewtonian Fluid Mechanics, vol. 71, no. 1-2, pp. 73-88, 1997.

[7] V. Gauri and K. W. Koelling, "Gas-assisted displacement of viscoelastic fluids: flow dynamics at the bubble front," Journal of Non-Newtonian Fluid Mechanics, vol. 83, no. 3, pp. 183-203, 1999.

[8] Q. C. Bi and T. S. Zhao, "Taylor bubbles in miniaturized circular and noncircular channels," International Journal of Multiphase Flow, vol. 27, no. 3, pp. 561-570, 2001.

[9] S. Y. Yang and H. L. Chou, "Study on the residual wall thickness at dimensional transitions and curved sections in gas-assisted molded circular tubes," Polymer Engineering and Science, vol. 42, no. 1, pp. 111-119, 2002.

[10] T. Yamamoto, T. Suga, K. Nakamura, and N. Mori, “The gas penetration through viscoelastic fluids with shear-thinning viscosity in a tube," Journal of Fluids Engineering, Transactions of the ASME, vol. 126, no. 2, pp. 148-152, 2004.

[11] R. G. Sousa, M. L. Riethmuller, A. M. F. R. Pinto, and J. B. L. M. Campos, "Flow around individual Taylor bubbles rising in stagnant polyacrylamide (PAA) solutions," Journal of NonNewtonian Fluid Mechanics, vol. 135, no. 1, pp. 16-31, 2006.

[12] C.-H. Hsu, P.-C. Chen, K.-Y. Kung, and C. Lai, "Impacts of ratio of asymptotic bubble width to diameter of circular tube and Reynolds number in a gas bubble driven flow," Chemical Engineering Science, vol. 60, no. 19, pp. 5341-5355, 2005.

[13] H. Ha-Ngoc and J. Fabre, "A boundary element method for calculating the shape and velocity of two-dimensional long bubble in stagnant and flowing liquid," Engineering Analysis with Boundary Elements, vol. 30, no. 7, pp. 539-552, 2006.

[14] C.-H. Hsu, C.-C. Chang, C.-C. Kuo, and K.-Y. Kung, "Transient response of long bubbles in volatile organic compounds," Journal of Marine Science and Technology, vol. 19, no. 5, pp. 541549, 2011.

[15] C.-H. Hsu, C.-C. Chang, C.-C. Kuo, and K.-Y. Kung, "Shape evolution of a long bubble penetrating liquids with various viscosities," Journal of Marine Science and Technology (Taiwan), vol. 21, no. 2, pp. 166-174, 2013.

[16] C. Chang, H. Lin, M. Lin, and T. Tsai, "Long bubble penetration through viscoelastic fluids in a suddenly contracting and expanding tube," Advances in Materials Science and Engineering, vol. 2016, Article ID 6702679, 9 pages, 2016. 

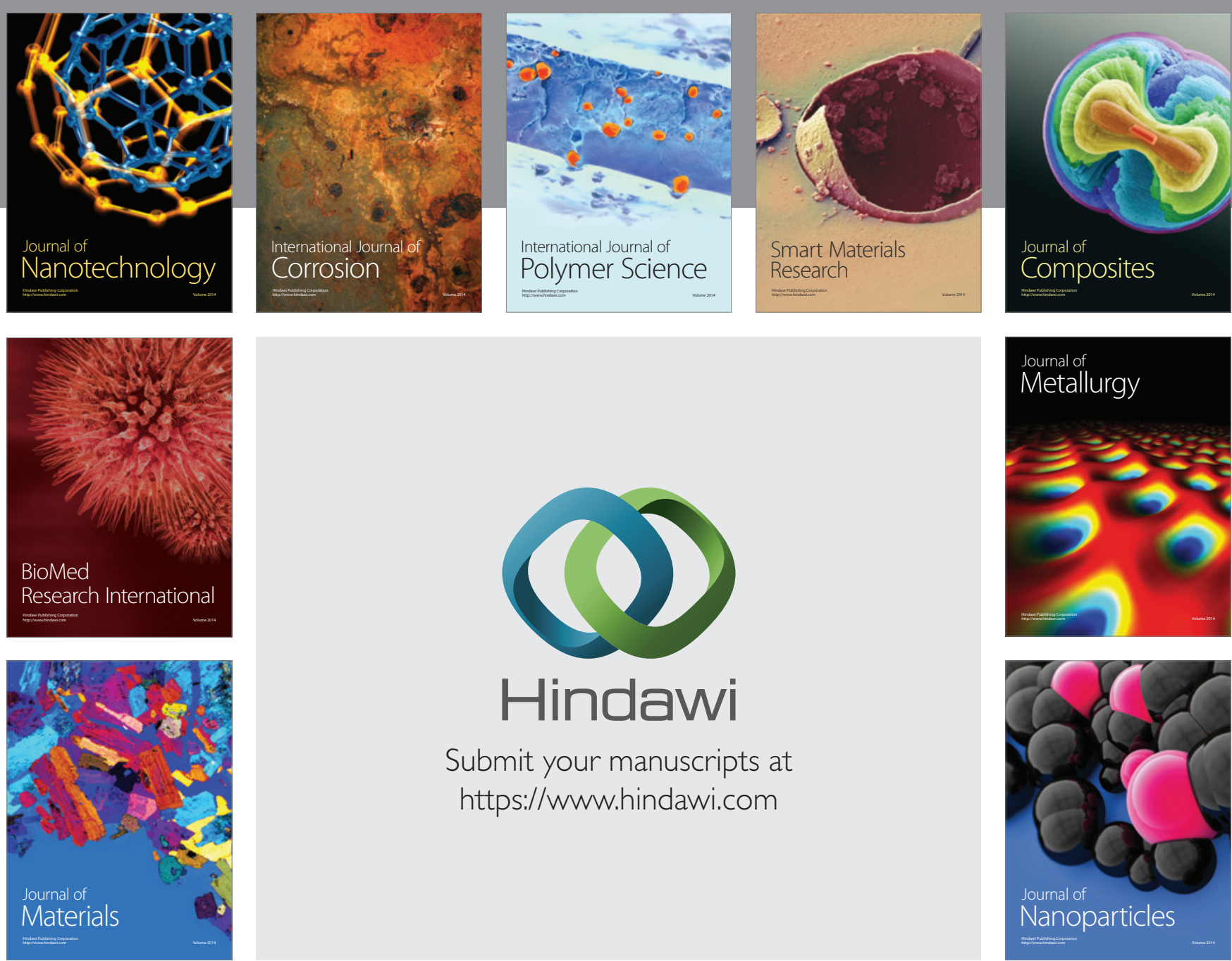

\section{Hindawi}

Submit your manuscripts at

https://www.hindawi.com

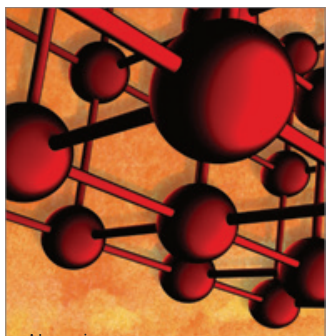

Materials Science and Engineering
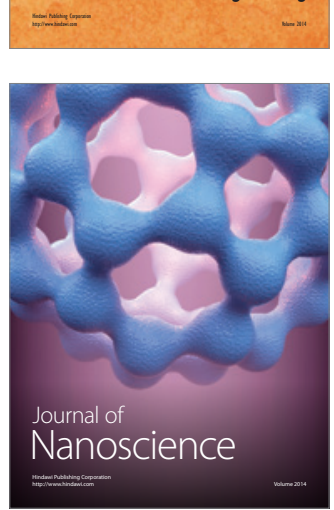
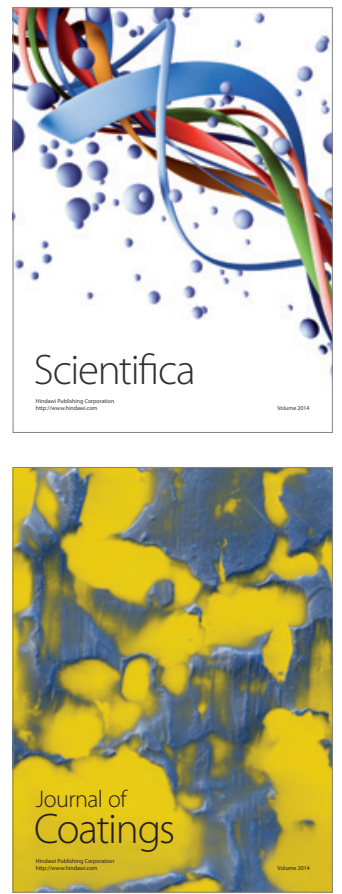
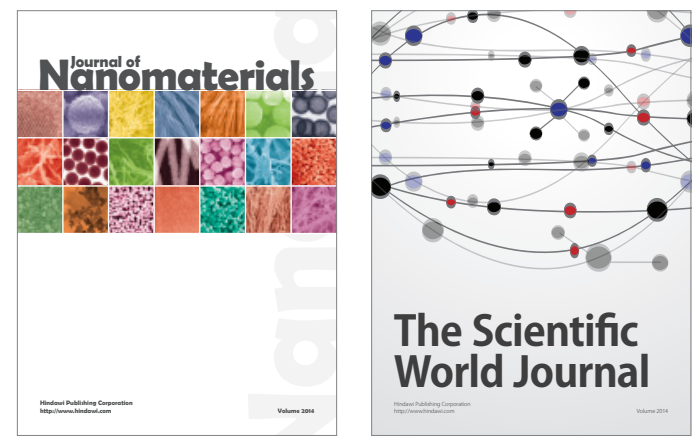

The Scientific World Journal
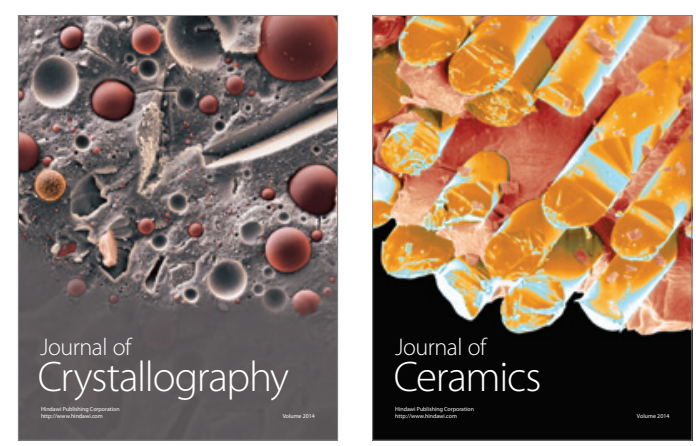
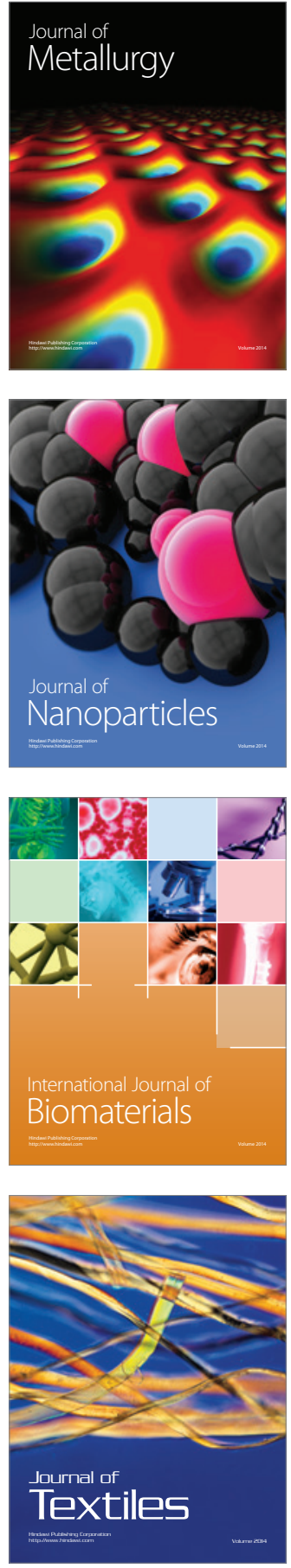